\title{
O CONSUMO E O NÃO CONSUMO: FLASHES DE UMA DISCUSSÃO
}

\section{El consumo y el no consumo: flashes de una discusión Consumption and non consumption: flashes of a discussion}

\author{
João Anzanello Carrascoza \\ Escola Superior de Propaganda e Marketing, São Paulo, Brasil. \\ Doutor e mestre em Ciências da Comunicação pela Escola de Comunicações e Artes da Universi- \\ dade de São Paulo (ECA-USP), com pós-doutorado em teoria literária pela Universidade Federal do \\ Rio de Janeiro (UFRJ). \\ E-mail: jcarrascoza@espm.br
}

RESUMO Nas últimas décadas, a concepção clássica de consumo - ato de aquisição de mercadorias - se ampliou a partir das reflexões de estudiosos de distintas áreas, como filósofos, antropólogos e sociólogos, sendo hoje entendida como um fenômeno sócio-cultural complexo. Neste artigo, objetivamos discutir aspectos epistemológicos do consumo e, igualmente, do não consumo de bens (materiais e simbólicos) a partir do conto Uma questão temporária, da escritora inglesa Jhumpa Lahiri. Vamos nos valer, para isso, de elementos da teoria literária e de preceitos da análise do discurso de linha francesa.

PALAVRAS-CHAVE Consumo, Comunicação, Literatura, Discurso.

RESUMEN En las últimas décadas, la concepción clásica de consumo -el acto de adquisición de mercancías- se ha ampliado a partir de las reflexiones de estudiosos de distintas áreas, como filósofos, antropólogos y sociólogos, siendo hoy entendido como un fenómeno socio-cultural complejo. En este artículo, objetivamos discutir aspectos epistemológicos del consumo y, igualmente, del no consumo de bienes (materiales y simbólicos), a partir del cuento Una cuestión temporal, de la escritora inglesa Jhumpa Lahiri, valiéndonos para ello de elementos de la teoría literaria y de preceptos del Análisis del Discurso de línea francesa.

PALAVRAS-CLAVE Consumo, Comunicación, Literatura, Discurso.

ABSTRACT In the last decades, the classical conception of consumption - the act of acquiring commodities - has expanded from the reflections of scholars from different areas, such as philosophers, anthropologists and sociologists, and is now understood as a complex socio-cultural phenomenon. In this article, we aim to discuss epistemological aspects of consumption and, equally, the non-consumption of goods (material and symbolic), from the short story A temporary question, by the English writer Jhumpa Lahiri, using for this reason elements of literary theory and the precepts of French Speech Analysis.

KEYWORDS Consumption, Communication, Literature, Speech.

\section{SE FAZ O ESCURO, A LUZ SE FAZ}

A célebre questão proposta por Shakespeare em sua peça Hamlet, "ser ou não ser", traz em seu bojo, ainda que implícita, a ideia de que "ser” (um) é também um "não ser” (outro). O ser, em sua condição de ser, 
é tudo o mais que ele não é: o mundo inteiro que é, fora dele, o seu não ser. O mesmo podemos dizer sobre os objetos - e os discursos que enunciam. O traço dialético entre o ser e seu não ser (que é o ser de outro) nos leva a pensar também nos ditos e não ditos discursivos.

No conto Iluminados, do livro O vaso azul (CARRASCOZA,1998), por exemplo, narramos um episódio protagonizado por um casal, em conflito: sentados, à noite, no sofá, diante da tevê; o marido e a mulher jantam sem trocar palavras, quando ocorre um blecaute que os lança de imediato à escuridão. Sem enxergar a comida no prato, a mulher busca na cozinha uma vela, que acaba por inaugurar, tão inesperadamente quanto o apagão, uma atmosfera de reaproximação entre ela e o homem. ${ }^{1}$ Os dois voltam a conversar e, como a luz não retorna senão horas depois, eles gastam o tempo na companhia um do outro, como havia tempos não o faziam, cuidando da louça e esquentando a água para o banho, que tomarão juntos, numa velha e inútil banheira. Sem o mundo alheio do vídeo, a vida do casal se reapresenta em busca de um concílio. É justamente no escuro fundo de uma relação conjugal em agonia que a chama da paz se aviva. Líquido, no sentido que lhe designa Bauman (2004), o amor se re-solidifica. Se antes esse casal produzia e consumia a distância, e, para que assim fosse, deixava, entre outras coisas, de produzir e consumir um renovado afeto, de súbito, à luz de velas, passa a fazê-lo, interrompendo a sua produção, ou "desconsumindo" a distância.

O nosso desafio aqui não é retextualizar a nossa própria história entendendo a retextualização (BETTETINI, 1996) como o deslocamento de um texto (o literário) para outro domínio (no caso, o científico) -, e, sim, retextualizar o conto Uma questão temporária, da escritora inglesa (de origem indiana) Jhumpa Lahiri. O conto é o primeiro de seu livro Intérprete de Males, pelo qual a autora ganhou o Prêmio Pulitzer, e nos permite abordar com maior profundidade nuances epistemológicas do consumo, em especial o seu "ser" que é, um consumo, e, simultaneamente, é um não ser; portanto, outro consumo. De forma coincidente, este conto, também protagonizado por um casal - Shoba e seu marido Shukumar -, assim se inicia.

A notificação informava que era uma questão temporária: por cinco dias a eletricidade seria cortada durante uma hora, a partir das oito da noite. Uma linha caíra na última tempestade de neve e os operários iam aproveitar as noites mais brandas para arrumá-la. $\mathrm{O}$ trabalho afetaria apenas as casas da tranqüila rua arborizada na qual Shoba e Shukumar moravam havia três anos... (LAHIRI, 2014, p. 9)

A ruptura na rotina do casal se dá quase de forma abrupta como em Iluminados - Shoba, ao chegar em casa, no fim da tarde, e ler o comunicado entre a correspondência, admite que havia sido "bondade deles ter avisado”," (LAHIRI, 2014, p.9), porque assim poderiam, ela e Shukumar, prepararem-se para as horas sem luz. A suspensão de energia começará naquela mesma noite, conforme constata o marido no calendário - e a transformação que promoverá na vida dos dois não será menos contundente, como veremos.

1. Explicamos com detalhes a gênese e a relevância desse conto em nossa poética no debate com o escritor Bartolomeu Campos de Queirós, reproduzido no livro Onde está a literatura? Seus espaços, seus leitores, seus textos, suas leituras (conferir Referências). 


\section{O NÃO CONSUMO DE UM BEM É O CONSUMO DE OUTRO}

Notamos, já no início da história, que esse casal também está em crise. Shukumar, com trinta e cinco anos, ainda estudante (medíocre) de mestrado, havia viajado, tempos atrás, até Baltimore para uma conferência acadêmica, incentivado pela própria Shoba que, então grávida, poderia entrar em trabalho de parto a qualquer momento.

Quando volta para casa, em Boston, Shukumar é surpreendido pelo fato de que o bebê nascera morto. A mulher se recuperaria e semanas depois estaria de novo em atividade, "nada indicava que não pudesse ter filhos no futuro" (LAHIRI, 2014, p.11), mas a vida entre os dois jamais seria como antes. Aos poucos, eles se tornaram "peritos em evitar um ao outro na casa de três quartos, passando o máximo de tempo possível em andares separados” (LAHIRI, 2014, p. 12).

E eis que ali estão agora, na escrita de Jhumpa Lahiri, procurando se mexer, já que são sete e meia e, às oito horas, o fornecimento de luz será interrompido. Antes que se apressem à procura de velas para que não jantem no escuro - e, dessa vez, inclusive, jantem juntos, já que cada um se servia no fogão e ia comer num canto da casa havia meses (Shoba na sala de estar, Shukumar no estúdio) -, vamos abordar por meio de fatos da trama e da atitude distinta dos personagens, que a narradora nos apresenta, o consumo pelo seu ser, ao mesmo tempo que é, também, todo um não ser.

Douglas e Isherwood (2006) apontam que o consumo não é imposto, é uma escolha livre. Os bens de consumo comunicam valores, estabelecem relações entre os indivíduos - pontes, que resultam em laços e alianças, e cercas, que os impedem. Ante a situação conjugal conflituosa, quanto mais tempo Shoba ficava fora, estendendo sua jornada de trabalho, mais Shukumar desejava permanecer em casa, "sem sair nem para pegar correspondência, ou comprar frutas ou vinho nas lojas perto do ponto do bonde” (LAHIRI, 2014, p. 10). Uma vez que escolheu consumir seu tempo dentro de casa, Shukumar optou por não consumir seu tempo de todas as outras maneiras. Se, por meio do consumo, o indivíduo diz alguma coisa sobre si e sobre o que o cerca, ele também o diz pelo seu não consumo.

Depois que o bebê morreu, marido e mulher deixam de se olhar nos olhos, de sussurrar um o nome do outro, os corpos cessam de se buscar antes de dormir, senão em raras ocasiões. Shukumar passa a consumir menos a companhia de Shoba e vice-versa. Ele, entediado e sem ânimo para avançar na escritura de sua dissertação, vai sair da cama, muitas vezes, só quase na hora do almoço - é essa a sua escolha, escolha que o faz ir à cozinha e pegar "o bule de café para tomar o resto que Shoba deixara para ele, ao lado de uma caneca vazia” (LAHIRI, 2014, p. 13). Essa sua prática de consumo - beber o café sozinho - produz um enunciado sobre a sua relação com a Shoba pois não lhe foi imposta por ninguém, sendo sua própria escolha, e nos lembra os versos, igualmente "significativos", do Poema só para Jaime Ovalle, de Manuel Bandeira, reproduzido a seguir.

Quando hoje acordei, ainda fazia escuro

(Embora a manhã já estivesse avançada).

Chovia.

Chovia uma triste chuva de resignação

Como contraste e consolo ao calor tempestuoso da noite.

Então me levantei,

Bebi o café que eu mesmo preparei, 
Depois me deitei novamente, acendi um cigarro e fiquei pensando...

- Humildemente pensando na vida e nas mulheres que amei.

(1996, p. 191)

Não foi Shukumar que fez o café, foi Shoba, mas ele prefere tomá-lo sempre quando ela já partiu para o trabalho. Se no poema de Bandeira o indivíduo está só, pensando nas mulheres que amou, então ausentes, no conto retextualizado a mulher está presente, mas o homem, cogitando se ainda a ama, está (por sua opção) só. O “eu” do poeta evoca no presente as mulheres (amadas) de seu passado, enquanto Shukumar evoca o passado, quando havia amor entre ele e a sua jovem esposa.

Pelo consumo (solitário) do café, sabemos que marido e mulher se mantêm afastados no presente, mas é também pelo consumo que o fato mais marcante do passado deles é alçado à memória por Shukumar, ou chamado a construir, em sonho, a futura vida familiar;

Toda a vez que ele pensava nesse momento, o último momento em que vira Shoba grávida, era do táxi que mais se lembrava, uma perua pintada de vermelho com letras brancas. Era ampla comparada com seu carro (...) Enquanto o táxi corria pela Beacon Street, pensara no dia em que ele e Shoba talvez tivessem de comprar uma perua para levar os filhos para as aulas de música e consultas no dentista. Ele se imaginara agarrado à direção, enquanto Shoba virava para trás para distribuir as caixinhas de suco para as crianças. (LAHIRI, 2014, p. 11)

Rocha (1990) nos diz que podemos não consumir o produto, mas na esfera midiática - onipresente da vida contemporânea na qual estamos imersos -, acabamos por consumir o discurso do produto às vezes até mais que o próprio. Se não podia ter uma "perua pintada de vermelho com letras brancas” (LAHIRI, 2014, p.11), que, maior que seu carro, se mostrava ideal para uma família, Shukumar podia pensar nela, desejar comprá-la um dia e, assim, escolhe consumir (imaginariamente) aquele produto e não outro.

O caderno de papel amarelo pautado em que Shukumar fazia anotações para a sua dissertação (por que não papel branco e sem pautas?), os paletós de tweed e calças de veludo (por que não casacos de lã e calças jeans?), o carneiro que ele cozinharia para o jantar daquela noite (por que não frango, ou peixe?), o batom vermelho-escuro de Shoba (por que não rosa claro?) e a sua mochila de couro (por que não uma bolsa de pano?); enfim, todo tipo de mercadoria que aparece no conto, bem como as palavras entrelaçadas no plano narrativo, nos mostram que o consumo de "A" é o não consumo de "B a Z".

\section{DITOS E NÃO DITOS. O CONSUMO COMO ENUNCIAÇÃO DO NÃO CONSUMO}

Se o consumo de um bem material é, no momento de seu consumo, o não consumo de todos os outros bens materiais (que poderiam ter sido escolhidos em seu lugar, mas não o foram), o mesmo podemos dizer do consumo simbólico, como o dos discursos, sejam eles do espaço público ou privado.

Os ditos de um discurso não podem ser senão o que são - seus referidos ditos -, abdicando de ser, pela escolha do enunciador, todos os demais 
ditos, então silenciados, que poderiam, no entanto, estar ocupando o seu lugar. Como assinala Orlandi (2000, p. 82-83):

Há sempre no dizer um não-dizer necessário. Quando se diz " $\mathrm{x}$ ", o não-dito "y" permanece como uma relação de sentido que informa o dizer de " $\mathrm{x}$ " (...) Além disso, o que já foi dito mas já foi esquecido tem um efeito sobre o dizer que se atualiza em uma formulação. Em outras palavras, o interdiscurso determina o intradiscurso: o dizer (presentificado) se sustenta na memória (ausência) discursiva.

Os não ditos à margem de todo o dizer também significam, e o que significam será dado pelo contexto. Já nessa primeira noite, tão logo o casal acaba de esquentar a comida, as luzes se apagam. Para não comer às escuras, Shukumar acende umas velinhas de aniversário que encontrou pela casa e o jantar assim se estende, com a mulher alimentando uma conversa a fim de retirar ambos de um silêncio angustiante que os tem envolvido no dia a dia. Depois de alguns minutos, Shoba propõe: "que tal a gente contar uma coisa que nunca contou para o outro?”. (LAHIRI, 2014, p.20) Tantos assuntos poderiam acorrer a esse diálogo dos dois e, no entanto, a "escolha" será justamente por aqueles que o marido e a mulher até ali haviam evitado partilhar um com o outro. Dessa vez vão chamar à lembrança fatos que viveram mas esconderam de seu par enunciados não ditos em momentos passados, quando então preferiram escolher outros ditos sobre si e que visavam, evidentemente, produzir certos efeitos de sentido.

Como Shukumar aceita o desafio, Shoba, então, começa dizendo: "a primeira vez que fiquei sozinha no seu apartamento, olhei sua agenda de endereços para ver se eu estava nele. Acho que a gente se conhecia fazia duas semanas” (LAHIRI, 2014, p. 20). Embora seu nome não estivesse lá, conforme constata na ocasião, ela diz ao marido "não desisti de você”. (LAHIRI, 2014, p.21). É o início de um “jogo” que propõe já a enunciação do conflito que o casal está atravessando. Shoba se vale do escuro para trazer à luz o problema que, nos últimos meses, os dois têm deixado à sombra. Shukumar entende no dito de sua mulher o não dito subentendido - é como se ela dissesse, novamente, "estou aqui, agora, porque não desisti de você”. Ele poderia desviar as águas da conversa para um curso diferente, mobilizando outro dizer - algum fato que ainda não contara a ela, sim, mas, como a regra do jogo não o obrigava a seguir o eco do primeiro enunciado, poderia ter confessado alguma coisa só dele, que não a envolvia.

Shukumar, entretanto, decide adotar a mesma "formação discursiva" e diz: "a primeira vez que nós saímos para jantar, no restaurante português, eu esqueci de dar gorjeta para o garçom. Voltei na manhã seguinte, descobri o nome dele, deixei o dinheiro com o gerente”. (LAHIRI, 2014, p. 21) A mulher lhe pergunta o motivo desse esquecimento e ele diz que, no fim daquele jantar, sentiu que poderia se casar com ela, o que o distraiu e o fez esquecer a gorjeta. Podemos interpretar, assim como Shoba, pelo não dito colado a esse dizer de seu marido, que ele "também" não desistiu do casamento com ela.

Os dois, graças às “condições de produção” de seu discurso, optam por enunciar, ou seja, produzir - e, por consequência, consumir - dizeres que, indiretamente, operam a esperança de que a ruptura amorosa, sentida pelos dois, embora não enunciada, pode ser afastada. Tanto é assim que, na noite seguinte, para que o jantar não seja à luz improvisada 
das velinhas de aniversário, Shoba compra pilhas para a lanterna e um pacote de velas.

O casal janta cedo, antes da suspensão da eletricidade, sob a luz do lustre de cobre pendurado no teto sobre a mesa, mas o "discurso" gestual, que insinua a re-aproximação, prossegue quando terminam a refeição. Nesse momento, Shukumar se surpreende ao ver a mulher "pôr seu prato em cima do dele e levar os dois para a pia. Ele achara que ela ia se retirar para a sala” (LAHIRI, 2014, p. 22) a fim de trabalhar. A casa logo fica às escuras, Shukumar acende as velas, ampliando a atmosfera romântica ideal para que eles deem mais um passo na tentativa da reconciliação ou rumo ao fim do casamento.

Acomodados nos degraus da escada externa da casa, ambos se põem a observar as pessoas que saem à rua com suas lanternas e, quando uma de suas vizinhas, a senhora Bradford, passa com o marido e os convida a ir até a livraria, Shoba e Shukumar respondem juntos "não, obrigado". (LAHIRI, 2014, p.23). Shukumar se surpreende novamente, agora pelo fato de que as suas palavras coincidiram com as de sua mulher, as suspeitas também o levam a mirar noutra direção.

Perguntou-se o que Shoba iria lhe dizer no escuro. As piores possibilidades já haviam lhe passado pela cabeça. Que ela tinha um caso. Que não o respeitava por ter trinta e cinco anos e ainda ser estudante. Que o culpava por estar em Baltimore, como a mãe dela culpava. Mas ele sabia que essas coisas não eram verdade. Ela era tão fiel quanto ele. Acreditava nele. Ela é que havia insistido que fosse para Baltimore. $\mathrm{O}$ que eles não sabiam a respeito um do outro? (LAHIRI, 2014, p. 23)

Esta dúvida de Shukumar "o que eles não sabiam a respeito um do outro?” (LAHIRI, 2014, p.23) nos remete, outra vez, aos enunciados ditos e aos não ditos, posto que, se os primeiros comunicam - e por eles passamos a saber coisas sobre as pessoas, como suas crenças e seus valores -, os segundos, por tudo o que não está expresso nos dizeres, igualmente comunicam.

Se o que eles não sabiam a respeito um do outro é verbalizado, ganhando o status do dizer - e, portanto, do saber -, os não ditos estão presentes emitindo seus novos sentidos em virtude do contexto alterado. Dando continuidade ao jogo iniciado na noite anterior, Shoba toma a iniciativa, outra vez, e diz: "uma noite, eu falei que ia trabalhar até tarde, mas saí com Gillian e tomei um Martini” (LAHIRI, 2014, p. 24). Naquela noite, Shukumar se lembrava, ele jantara sozinho com a mãe, que viera visitar o casal por duas semanas; ela queria, junto ao filho, homenagear o marido, morto havia anos. Nas noites anteriores, sempre quando preparava a comida de que o falecido gostava, a mãe de Shukumar chorava com as carícias que Shoba fazia em sua mão.

O filho recordava seu sentimento da época, querendo que a esposa estivesse em casa "para dizer as coisas certas porque ele só conseguia dizer as coisas erradas” para sua mãe,, no entanto, “ele agora imaginava Shoba com Gillian num bar com sofás de veludo listrado, aquele a que costumavam ir depois do cinema, cuidando para o drink ter uma azeitona a mais, pedindo um cigarro a Gillian” (LAHIRI, 2014, p. 24); além disso, fora Gillian (amigo dela) quem tinha levado Shoba no hospital para fazer o parto.

Como os sentidos de todo e qualquer discurso resultam de sua relação com outros discursos, e "um dizer tem relação com outros 
dizeres realizados, imaginados ou possíveis" (ORLANDI, 2005, p. 39), um fato, também grave, que Shukumar escondeu de Shoba, e que ainda o perturbava, era ter colado num exame da faculdade, quinze anos antes. Ele sente alívio ao confessar essa sua falta, valendo-se não da mesma formação discursiva de Shoba, mas de outra. Shukumar se pergunta, mentalmente, se ela se incomodaria com o que ele acabara de dizer. Como se captasse tal pergunta no silêncio que se faz entre ambos, ou seja, como se o não dito ao redor do dizer o dissesse claramente, ela - depois de olhar os mocassins velhos que ele usava como se fossem chinelos responde com um gesto, um enunciado daquela que poderíamos afirmar ser a sua formação discursiva (amorosa): Shoba lhe pega a mão e a aperta.

Quando a luz volta, às nove horas da noite, as pessoas do bairro aplaudem e começam a ligar a televisão - retornando ao consumo midiático. Shoba e Shukumar se levantam e entram em casa, "a mão dele ainda na dela”. (LAHIRI, 2014, p.25) Com esse enlace das mãos, o narrador de Uma questão temporária está anunciando que os dois, ao menos daquela vez, entregaram-se mutuamente ao perdão.

Nas noites seguintes, o casal continuou a produzir e consumir confissões, "miudezas com que haviam magoado ou decepcionado um ao outro e a si mesmos" (LAHIRI, 2014, p. 25). Shukumar contou que, quando Shoba estava no final da gravidez, com a barriga imensa, e ele não podia mais tocá-la, recortou a foto de uma mulher numa revista de moda e, mirando-a às vezes, sentia intenso desejo: "foi o mais perto que chegou da infidelidade" (LAHIRI, 2014, p. 26). Shoba reage pegando na mão do marido e apertando-a, como tinha feito antes. Por isotopia, seu gesto enuncia, novamente, que ela o perdoa.

Quando a casa ficava às escuras, os dois conseguiam não apenas conversar um com o outro, como há tempos não o faziam, e o consumo das sombras, ante o não consumo da luz, levou-os do encontro com as palavras ao encontro dos corpos: na terceira noite, depois das confidências, Shukumar se põe desajeitadamente a beijar Shoba; na quarta noite, "subiram cuidadosamente a escada, até a cama, tateando juntos com os pés no último degrau antes do patamar e fazendo amor com um desespero que tinham esquecido" (LAHIRI, 2014, p. 27).

A expressão "no último degrau antes do patamar" (LAHIRI, 2014, p.27) revela que o caminho percorrido pelo casal na tentativa de se reconciliar chegou mesmo ao seu último lance, pois na manhã da quinta noite, Shukumar encontra um novo comunicado da companhia de eletricidade na caixa de correspondência, avisando que o problema havia sido solucionado antes do prazo. O consumo do "escuro" o motivara a fazer um jantar especial, planejando preparar um malai de camarão para Shoba mas, com as luzes acesas, não seria a mesma coisa - ou, nos termos da análise de discurso, esse "enunciado" não produziria, diante do novo contexto, os mesmos efeitos de sentido.

Embora o “jogo" tenha acabado, o casal prefere jantar à luz de velas, reproduzindo a atmosfera das noites anteriores. Comem todo o camarão, abrem a segunda garrafa de vinho e Shukumar põe um disco, um álbum de Thelonious Monk que Shoba gostava.

Então, dá-se o desfecho inesperado: Shoba apaga as velas e acende a luz. O marido tenta convencê-la a deixar a luz apagada, mas ela diz: "quero que você veja o meu rosto quando eu te disser o que vou dizer" (LAHIRI, 2014, p. 28). Shukumar sente seu coração acelerar pois, no dia em que ela lhe dissera que estava grávida, tinha usado as mesmas palavras, com o mesmo tom suave. 
- Andei procurando apartamento e encontrei um - disse ela, apertando os olhos aparentemente para olhar alguma coisa atrás do ombro esquerdo dele. A culpa não era de ninguém, ela continuou. Tinham passado por muita coisa. Ela precisava de algum tempo sozinha. Tinha economizado dinheiro numa conta de poupança. $\mathrm{O}$ apartamento ficava em Beacon Hill, de forma que podia ir a pé para o trabalho. Ela havia assinado o contrato essa noite, antes de voltar para casa. (LAHIRI, 2014, p. 28-9)

Shukumar sente alívio, mas também aversão com essas palavras de Shoba. Ele não havia compreendido, à margem dos dizeres dela até então, que os não ditos enunciavam aquela sólida certeza: que sua mulher estava se "preparando para uma vida sem ele". (LAHIRI, 2014, p.29) Só então se dá conta de que "era isso que ela tinha tentado lhe dizer nas últimas quatro noites, "Era o motivo do jogo dela” (LAHIRI, 2014, p. 29). Tanto quanto o que eles consumiram nesse jantar - o camarão, o vinho, a penumbra - é o não consumo de tudo o mais que foi excluído, os enunciados ditos por ambos até aquela noite são os não ditos que ocultavam toda a verdade. Ou quase toda, porque era a vez de Shukumar fazer também a sua última confissão.

Ao contrário do que Shoba pensava, ele não havia chegado do congresso de Baltimore quando ela dormia na cama do hospital e o bebê já fora cremado, mas antes, a tempo de vê-lo, de segurá-lo, ainda que morto em seus braços: “- Nosso bebê era um menino - ele disse. - A pele dele era mais vermelha que marrom. Tinha cabelo preto. Pesava quase três quilos. A mão estava fechada, como a sua durante a noite” (LAHIRI, 2014, p. 30).

Shukumar deixa à escura, em seu dizer, todos os incontáveis enunciados possíveis naquele contexto para acender o único capaz de mostrar o quanto ele conhecia Shoba, contando a ela que a mão do bebê "estava fechada, como a sua durante a noite". (LAHIRI, 2014, p.30). Agora ela sabia de tudo.

Ele tinha carregado seu filho, que só conhecera a vida dentro dela, tinha apertado o bebê ao peito numa sala escura de uma ala desconhecida de um hospital. Tinha ficado com ele nos braços até uma enfermeira bater na porta e levá-lo embora, e prometera a si mesmo naquele dia nunca contar a Shoba, porque ele ainda a amava então e era a única coisa na vida que ela quisera que fosse uma surpresa. (LAHIRI, 2014, p. 30)

Os dizeres, tanto quanto os não dizeres, os levam a saber mais um do outro, como o consumo, ou o não consumo, seja do que for, também nos leva a saber algo de quem, por escolha, o consuma.

Shoba apagou a luz da sala. Shukumar sentou-se ao lado dela. E, finalizando a história, "os dois choraram juntos, pelas coisas que agora sabiam” (LAHIRI, 2014, p. 30).

Se em Iluminados, o casal se reaproxima, ao verbalizar e, assim, consumir pela lembrança, fatos felizes de seu passado, em Uma questão temporária, marido e mulher por meio do jogo da verdade, enunciando vivências de cada um até então nunca narradas ao outro. Ambos ativam o consumo mútuo de confidências, tirando o não dito de todas as possibilidades em que repousa e trazendo-o para o dizer, dizer que, se vai conduzi-los a uma reaproximação ou ao afastamento definitivo, os obrigará, de qualquer forma, a assumir uma nova vida. 
Se o bebê de Shukumar e Shoba não conheceu a luz da vida e a sua morte provocou um blecaute na antes relação harmoniosa do casal, o escuro de umas poucas horas, em virtude da falta de eletricidade, obrigou marido e mulher a irem ao fundo de suas motivações para salvar o amor em agonia ou matá-lo de vez. Ser (ou não ser) o amor de um para o outro. No escuro, os dois descobrem que ser um (o amor) é não ser outro (o desamor) e vice-versa, como a luz que é luz por não ser sombra, como o consumo que, por ser "A", é o não consumo de tudo o que não é "A".

\section{PELA PRESERVAÇÃO DAS RESERVAS DE ESCURO}

Uma cigana, no conto A profecia de Arthur Miller, diz, a certa altura, a uma consulente, que o futuro "é uma planície, uma planície sem fim, e não o que tínhamos pensado - uma montanha com uma glória no alto" (MILLER, 2015, p.161-162).

O que somos agora é tudo o que fomos antes, no passado, até o momento presente. Tudo o que seremos é o que somos, até um minuto antes de ser, no minuto futuro. A vida que consumimos também nos consome, como seres que são um e não outro. O que consumimos no dia a dia, e mesmo durante toda a nossa existência, como uma trama discursiva, enuncia e anuncia quem fomos, somos e seremos.

É no escuro que Shukumar e Shoba se lançam à produção e ao consumo de "segredos" que, queiram ou não, põem às claras as mágoas que haviam decantado nas sombras de um convívio frio e distante. Assim como há reservas colossais de beleza e poesia em nosso prosaico cotidiano, há igualmente reservas de escuro inexploradas, capazes de iluminar situações de consumo que podem mudar a nossa história criando tanto pontes quanto cercas.

O consumo (e o não consumo) é como a nossa vida, que, a cada mudança, nos torna um ser, e, ao mesmo tempo, todos os outros não ser. O consumo se revela provisório, tanto quanto o nosso viver, que, se é um nesse agora, pode ser outro no instante seguinte. Vivendo a vida, produzimos e consumimos um eu, deixando, portanto, de produzir e consumir outros tantos eus. Se produzimos e consumimos um mundo, renunciamos a todos os outros milhares de mundos.

De definitiva em nossa vida, cuja condição é e sempre será provisória, só a certeza de que é possível passarmos de um ser para outro, e o consumo, aceitemos ou não, pode ser um agente que consubstancia essa mudança.

\section{REFERÊNCIAS}

BANDEIRA, M. Estrela da vida inteira. São Paulo: Círculo do Livro, 1996.

BAUMAN, Z. Amor líquido: Sobre a fragilidade dos laços humanos. Rio de Janeiro: Zahar, 2004.

BELMIRO, C. A.; MACIEL, F. I. P.; BAPTISTA, M. C; MARTINS, A. A. Onde está a literatura? Seus espaços, seus leitores, seus textos, suas leituras. Belo Horizonte: Editora UFMG, 2014.

BETTETINI, G. La conversación audiovisual. Barcelona: Cátedra, 1996. O vaso azul. São Paulo: Ática, 1998.

DOUGLAS, M.; ISHERWOOD, B. O mundo dos bens. Rio de Janeiro: Editora UFRJ, 2006.

LAHIRI, J. Intérprete de males. São Paulo: Biblioteca Azul, 2014.

MILLER, A. Eu não preciso mais de você e outros contos. São Paulo: Cia das Letras, 2015. ORLANDI, E. P. Análise de discurso: princípios e procedimentos. 2. ed. Pontes: Campinas, 2000. 